\title{
QUALITY ASSESSMENT OF SPHERICAL PANORAMIC IMAGES
}

\author{
VALORACIÓN DE LA CALIDAD DE IMÁGENES PANORÁMICAS ESFÉRICAS \\ Peyman Javadi*, José Luis Lerma, Luis García-Asenjo, Pascual Garrigues \\ Department of Cartographic Engineering, Geodesy, and Photogrammetry, Universitat Politècnica de València, Camino de Vera s/n, \\ 46022 Valencia, Spain. pjavadi@doctor.upv.es; jllerma@cgf.upv.es; lugarcia@cgf.upv.es; pasgarta@cgf.upv.es
}

\begin{abstract}
:
In recent years, the production of panoramic images has been boosted by the increasing use of digital photographic cameras and mobile phones. However, for highly demanding applications such as long-range deformation monitoring, the accuracy and quality control of panoramic images and processes used to obtain accurate 3D models should be properly assessed. Therefore, prior to being applied in real projects, the quality of the spherical panoramic images generated by three widely used computer programs (Agisoft Metashape, GigaPan Stitch and PTGui) is evaluated using the same images of a photogrammetric laboratory full of control points and an outdoor environment by shooting from several stations. In addition to the assessment of the geometrical accuracy, the study also includes important aspects for practical efficiency such as workflow, speed of processing, user-friendliness, or exporting products and formats available. The results of the comparisons show that Agisoft Metashape meets the required geometric specifications with higher quality and has clear advantages in performance if compared to the other two tested programs.
\end{abstract}

Key words: spherical panorama, image-based monitoring, spherical photogrammetry, Panoramic Software, Panoramic Images, Deformation monitoring

\section{Resumen:}

En los últimos años, la producción de imágenes panorámicas se ha visto impulsada por el uso cada vez mayor de cámaras fotográficas digitales y teléfonos móviles. Sin embargo, deben evaluarse adecuadamente en aplicaciones altamente exigentes como la monitorización de deformaciones a grandes distancias, la precisión y el control de calidad de las imágenes panorámicas y los procesos utilizados para obtener modelos 3D precisos. Por consiguiente, antes de ser aplicadas en proyectos reales, se evalúa la calidad de las imágenes panorámicas esféricas generadas por tres programas informáticos ampliamente utilizados (Agisoft Metashape, GigaPan Stitch y PTGui) utilizando las mismas imágenes de un laboratorio fotogramétrico lleno de puntos de apoyo y del exterior desde varias estaciones. Además de la evaluación de la precisión geométrica, el estudio también incluye aspectos importantes para la eficiencia práctica como es el flujo de trabajo, la velocidad de procesamiento, la facilidad de uso o la exportación de productos y los formatos disponibles. Los resultados de las comparaciones muestran que Agisoft Metashape cumple con las especificaciones geométricas requeridas con mayor calidad y tiene claras ventajas de rendimiento si se compara con los otros dos programas testeados.

Palabras clave: panorama esférico, monitorización con imágenes, fotogrametría esférica, software de panorámicas, imágenes panorámicas, monitorización de la deformación

\section{Introduction}

In the last decades, the enhancement of technology and computing power have made panoramic images very popular in applications involving digital cameras o mobile phones. Furthermore, photogrammetry is increasingly used in fields that demands higher levels of accuracy and reliability such as historical documentation of cultural heritage, medical sciences or structural deformation monitoring (Barbero-García et al. 2020; Di Stefano et al. 2020). However, these demanding applications require the photogrammetric processes to be optimized in terms of efficiency, accuracy and overall cost. Thus, the proper testing and selection of software that is used to build the panoramic images that are subsequently used to obtain accurate 3D models become crucial for engineering or research applications. In this article, we examine the performance and output quality of the panoramic images produced by three widely used programs: Agisoft
Metashape, GigaPan Stitch and PTGui. In particular, the comparison puts a special focus on their ability to produce panoramic images with the necessary accuracy and quality for high-precision photogrammetric tasks.

The technique of image stitching offers the very interesting possibility of obtaining spherical imagery simply by merging a set of planar pictures, taken from the same point and partially overlapping. This system was invented in the 1990s by Apple Computer to improve the poor resolution of the digital cameras available at that time. The advantages of this technique are the low-cost equipment and distortion-free images which do not require the traditional interior orientation that is embedded in the stitching process, while the disadvantages are mainly due to potential alignment errors which could degrade the survey results (Fangi and Nardinocchi 2013).

The main reason for spherical misalignment is the inevitable image distortion created by the direct angular

*Corresponding Author: Peyman Javadi, pjavadi@doctor.upv.es 
protrusion. When it comes to sewing images and forming spherical panoramic images, the speeded-up robust features (SURF) method performs better than other existing methods such as scale-invariant feature transformation (SIFT) which makes matching between planar and spherical panoramic images possible and also facilitate the 2D-to-3D correspondence with LIDAR data (Chuang and Perng 2018).

Alternatively, we can use the oriented fast and rotated BRIEF (ORB) features method for stitching images. In this method, the ORB feature points are extracted by FAST with directional information, described by BRIEF, matched by the Hamming distance, and the RANSAC algorithm is used to remove the mismatched points. The key advantage of the method is that it overcomes the limitations of speed usually found in traditional stitching methods so that it can achieve a high matching performance. Also, solved the scale-invariant on the image stitching (Szeliski 1996; Xiong and Turkowski 1998; Wang et al. 2017).

Flexibility and efficiency are two important features for close-range architectural photogrammetry. Spherical photogrammetry (SP) proved to be fast, reliable, and accurate enough. However, an optimal selection of the photo scale with regard to the object distance is crucial for the improvement of efficiency and accuracy. Moreover, the use of narrow-angle (NA) lenses, which are required for distant points, limits the field of view (FOV) of the panorama to a few degrees, thus weakening the geometry if compared to that provided by wide angle (WA) ones. Therefore, a bad estimation of both the focal lens and the location of the station point can spoil the accuracy of the plotting (Fangi 2010).

Spherical photogrammetry can be considered a low-cost technique for three reasons: first, the equipment is reduced to a minimum of three elements: a digital camera, a tripod and a meter; second, there is no need for monumentations; third, the whole process of taking images is fast (Fangi 2015).

Concerning the use of panoramic cameras (e.g. OmniCamera Panono 360), which would alleviate the need of going through the stitching procedure, they lead to a couple of advantages. First of all, efficiency is clearly improved since stitching images is a time-consuming process. Second, their panoramas are ready to be used, being geometrically more correct than a panorama created with the dedicated software. Therefore, this type of cameras is a preferred solution for architectural heritage, especially for indoor environments. The methodology, however, presents some drawbacks. Usually, the accuracy values of the point cloud may not be acceptable. In fact, even if the residuals from the Ground Control Points (GCP) are admissible for architectural scales of representation, the reprojection error could be quite high, leading to a bit coarse point cloud (Fangi et al. 2018).

An additional approach is the use of spherical convolution with a generator that is designed to preserve the fidelity of the panoramic image under the generative adversarial networks (GANs) framework. Meanwhile, a highresolution panoramic image is generated by only using the sparse sketch map as input. Their approach can be used in several applications. For example, in communication systems, the transmitted data comprise the sketch map (Duan et al. 2020).

In conclusion, the process of building panoramic images is not trivial due to the range of different approaches that can be implemented in the software. Therefore, if the panoramic images are to be used for high-accuracy applications, it is crucial to validate the program used to generate them by using well-controlled sites with conditions as similar as possible to those that are expected in the fieldwork.

In the following section, the indoor lab and the outdoor test field that were used to assess and validate Agisoft Metashape, GigaPan Stitch and PTGui are described.

\section{Materials and methods}

\subsection{Materials}

A calibration laboratory was prepared by adapting a classroom. This indoor space was equipped with coded targets which were properly installed on the walls, ceiling and floor so as to obtain an optimal geometry for the photogrammetric calibration. Four stations were determined. One station in the centre and three stations approximately in the corners of the classroom. A fullframe Canon 1Ds Mark III camera with a $24 \mathrm{~mm}$ lens mounted on a GigaPan Stitch rotating motor and a fixed tripod were utilized. A Leica TS-06 Total Station was used to determine the coordinates of all the coded targets and the four stations in the same frame. A sketch of the classroom and the tools used are illustrated in Figures 1 and 2.
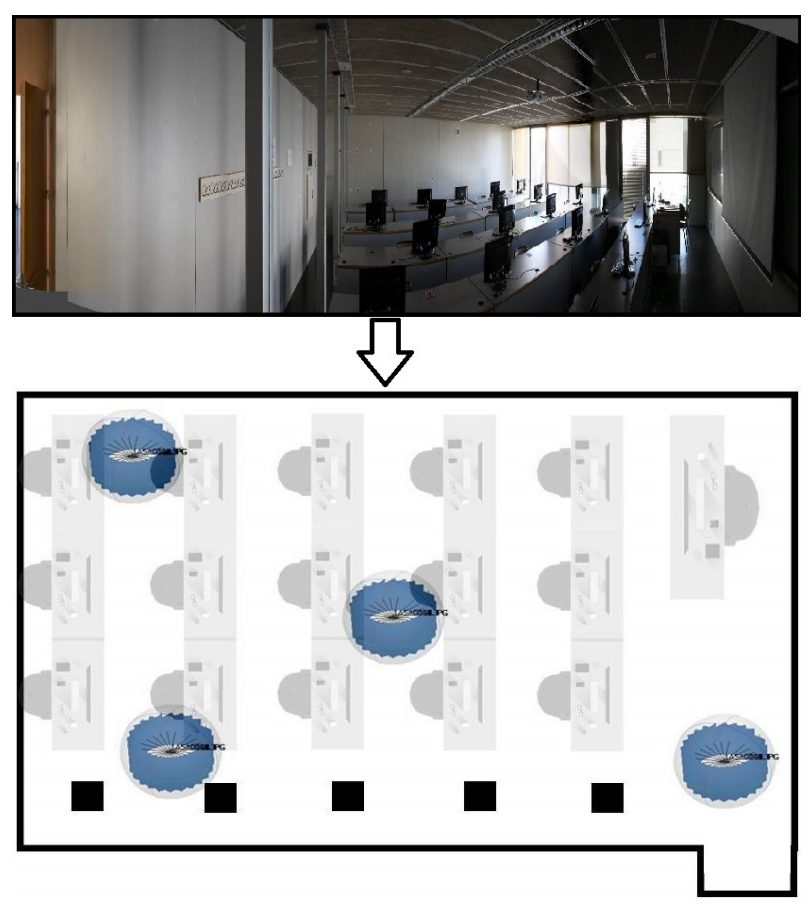

Figure 1: Classroom interior environment for photography.

In the outdoor test field, which is located in the campus of the Universitat Politècnica de València, the camera and Gigapan were set up on the existing pillars. Similarly, to the indoor experiment, four stations were selected to collect the required images for creating the panoramic photographs (Fig. 3). 


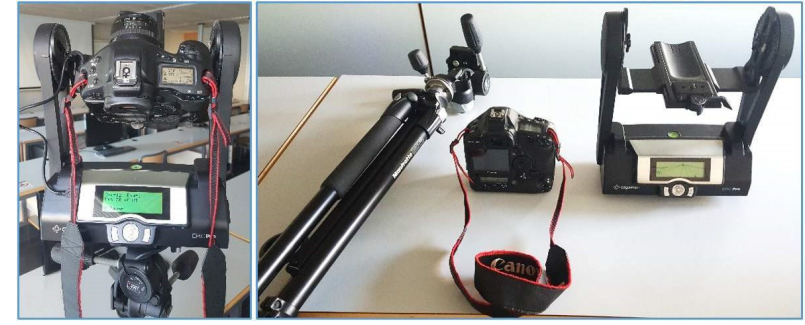

Figure 2: Tools used for taking the panoramic photography.

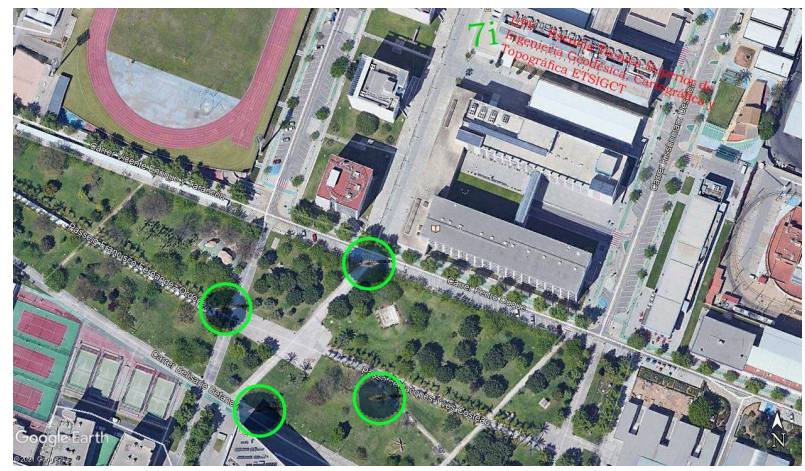

Figure 3: Outdoor environment for photography (UPV campus).

Image processing was performed using three software Agisoft Metashape, GigaPan Stitch and PTGui in the photogrammetry laboratory which will be discussed in the following section.

\subsection{Method: Creation of Panoramic Images}

Since the main objective behind this project is to create spherical panoramic images with high accuracy and good geometry, it is crucial to stitch the images together with high accuracy, which in turn requires correct matching of images and parallax prevention. In this research photography is frame by frame with the correct overlap on several stations with coded targets based on the same coordinate system and production of spherical panoramic images. To increase the accuracy of the work, 34 points were surveyed from the coded targets with a total station to be used both as control points and to integrate the coordinate system of the stations in the alignment of spherical panoramic images in relation with each other. The aforementioned software was used to create panoramic images. Photography inside the classroom was done around the horizon on several top-down strips. Seven strips were taken in the vertical direction with $60 \%$ overlap and twelve photos in the horizontal direction with $60 \%$ overlap according to Figure 4.
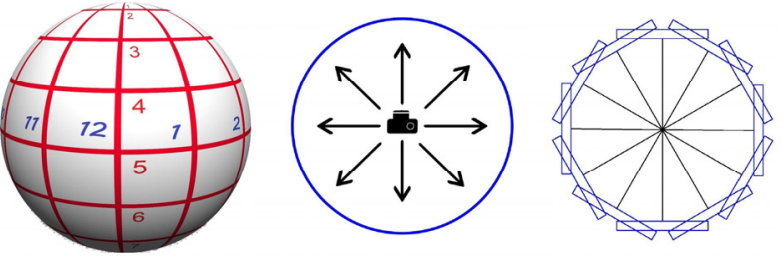

Figure 4: Method and number of photos taken at each station within the classroom.

In terms of software and output quality, if you are shooting with a GigaPan panorama robotic device, a software called GigaPan Stitch is available for stitching images and producing panoramas. This software belongs to the same company. In general, the capabilities and functionality of GigaPan Stitch software were expected to complement its device. The user interface of this software is very simple, but due to the possibility of photography multi-row (or multi-column) panoramas by GigaPan robotic devices, it is possible in GigaPan Stitch software to import and process multi-row panoramas. The remarkable thing about this software is that the quality of the produced panoramic images is reduced and, in some parts, the stitching of consecutive images is not done properly and the image parallax error is seen in parts of the panoramic image (Fig. 5).

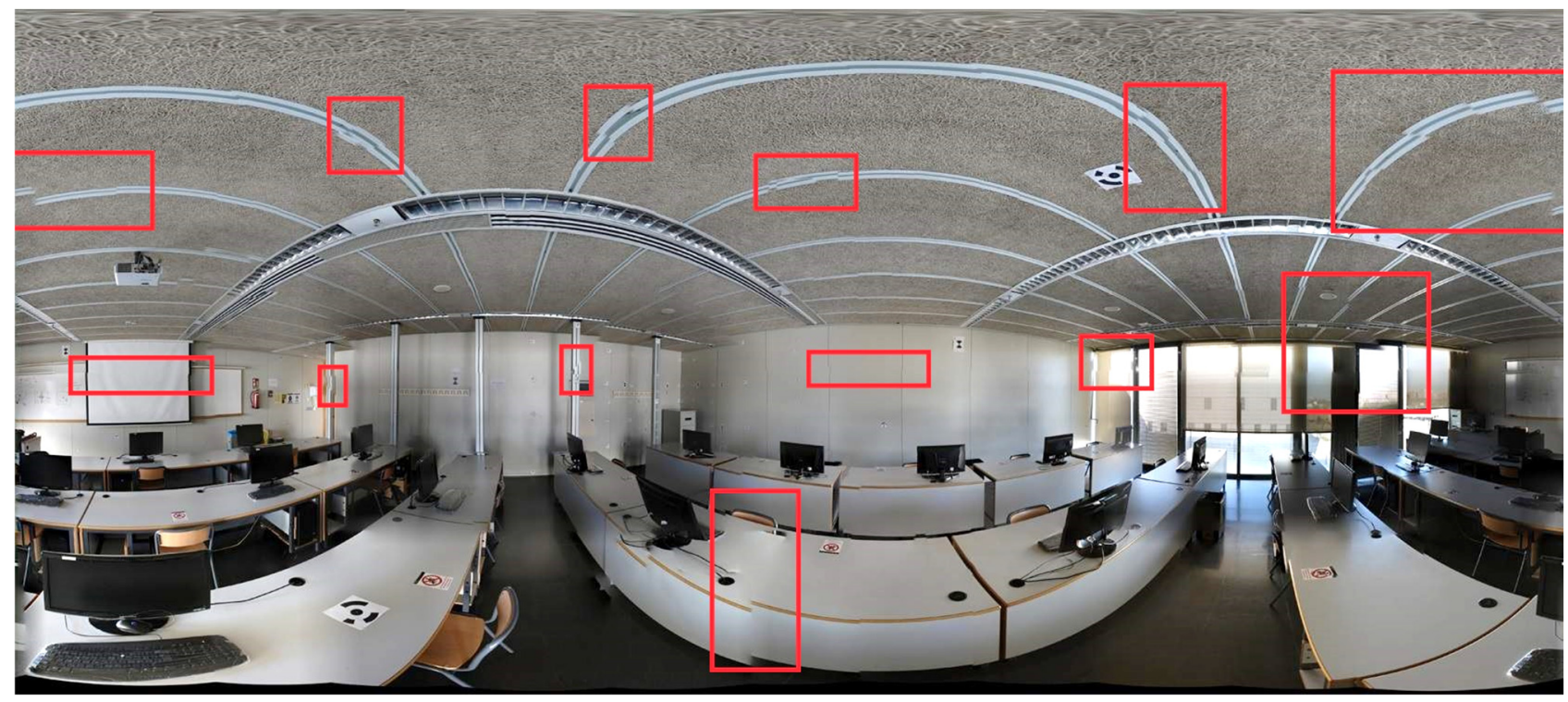

Figure 5: Spherical panoramic image made by GigaPan Stitch software.

In addition to GigaPan Stitch, we used PTGui software. At first glance, it looks like simple software, but it should be noted that it currently has significant capabilities compared to other software. It offers many options in all 
cases of masking out unwanted elements, manually editing control points, straightening horizons and working with multi-row panoramas. If you have taken pictures with multiple exposures, it can be also worked with high dynamic range (HDR) panoramic images, but it should be noted that the artistic and photographic aspects of this software are more than its technical and geometric parts. If you want to have maximum control over your panorama, it takes a long time to get the best results due to its user interface. Perhaps the most important advantage of this software over GigaPan Stitch geometrically is the ability to insert control points. Also, by entering the control points and adjusting the required items, the discrepancy in some parts of the final panoramic image can be seen in Figure 6.

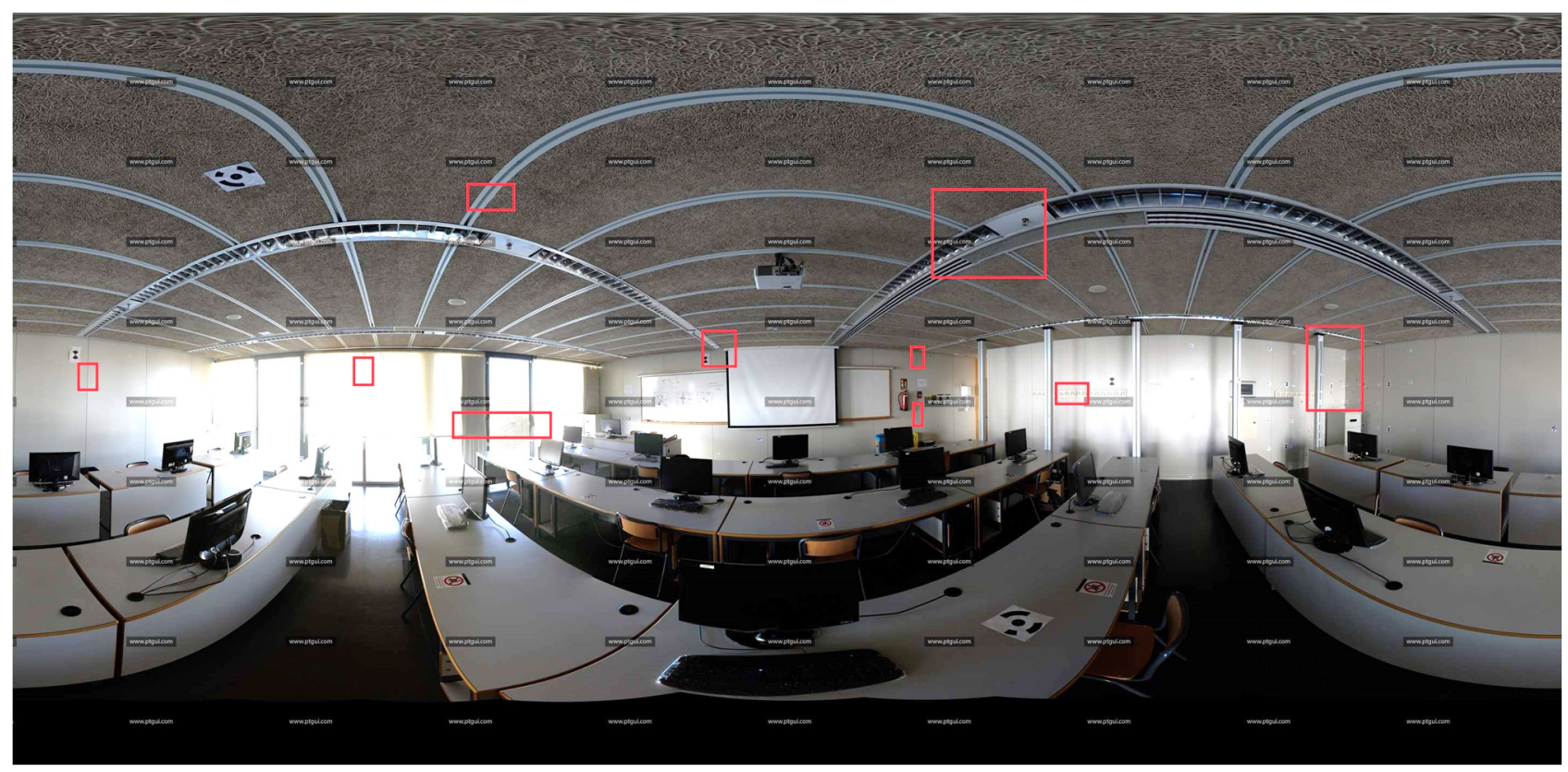

Figure 6: Spherical panoramic image made by PTGui software.

Panoramic images were also produced by using Agisoft Metashape software. This software provides many capabilities to the user, which will be discussed in detail. But again, our goal is to produce high-precision, highquality panoramic images for use in real and measurable projects. Close-range/long-range triangulation, polygon model generation, coordinate system adjustment, use of more than one camera in project creation and image processing together, creation of cloud points, 3D model production, camera calibration, adding control points, automatic reading of coded targets as well as adding markers manually and some other options are some of its outstanding features. Therefore, after importing the photos into the software and also defining the control points and making the necessary settings, a spherical panorama output was prepared, which was a much more desirable and higher quality result than the obtained with the previous two softwares (Fig. 7).

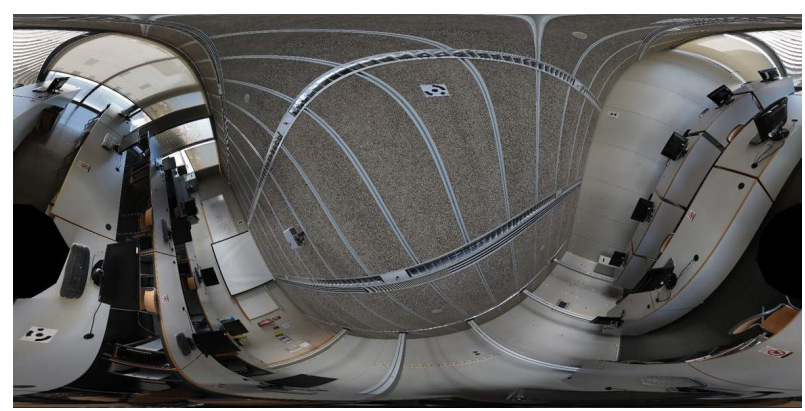

Figure 7: Spherical panoramic image made by Agisoft
After creating spherical panoramic images in the Agisoft Metashape software, four panorama images obtained from the four stations were entered into the software to orient them to each other. Using markers as well as control points, the panorama images were oriented, as shown in Figure 8.

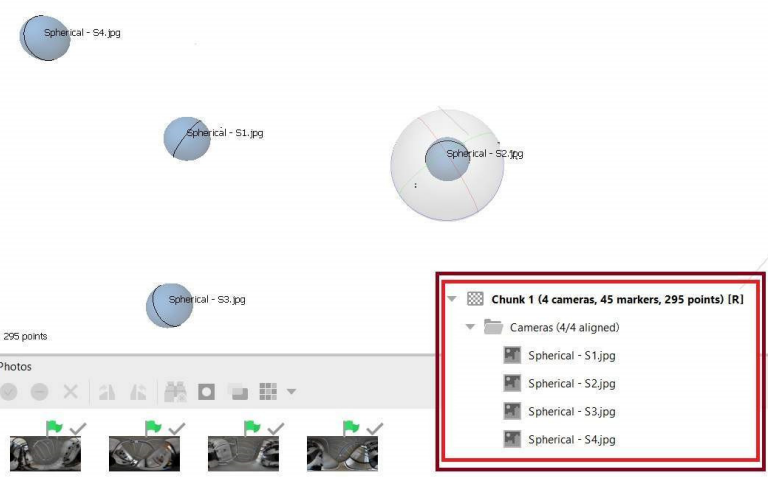

Figure 8: Orientation of four spherical panoramas made by Agisoft Metashape software.

Due to the high quality and accuracy of this software, in addition to the spherical panorama mode, a panorama with one horizontal strip was also made. As in the previous step, one strip panorama was entered into software for each station and oriented to each other using control points and markers, which can be seen in Figure 9. 


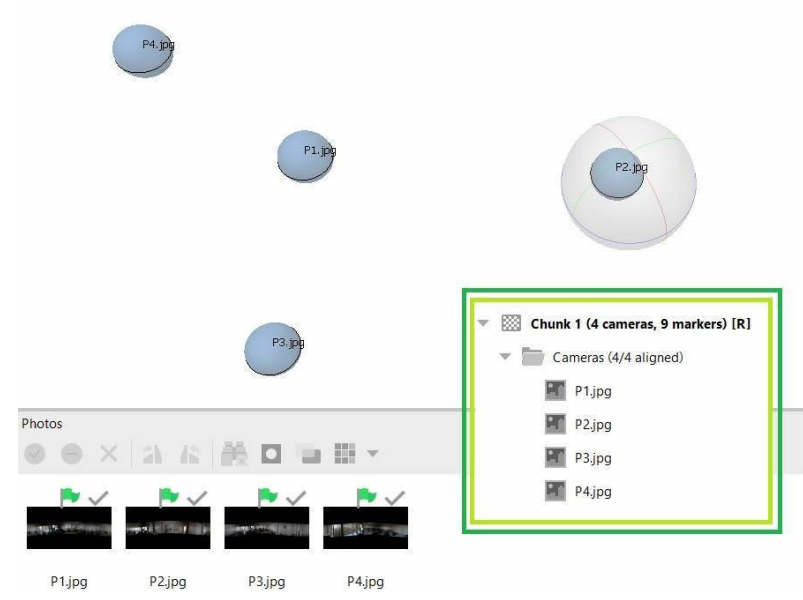

Figure 9: Orientation of four one strip panoramas made by Agisoft Metashape software relative to each other.

Due to the good quality obtained in the production of panorama images from Agisoft Metashape software, panoramic images of the UPV campus in the area previously shown in Figure 3 were produced only with this software (Fig. 10). Photography on the campus was done with only one strip around the horizon and on four fixed pillars. The photos were entered into the software as frames and the images of each station were aligned to each other (Fig. 11).

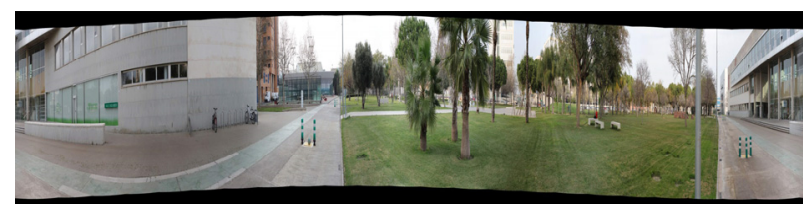

Figure 10: Panoramic image made by Agisoft Metashape software from UPV campus.

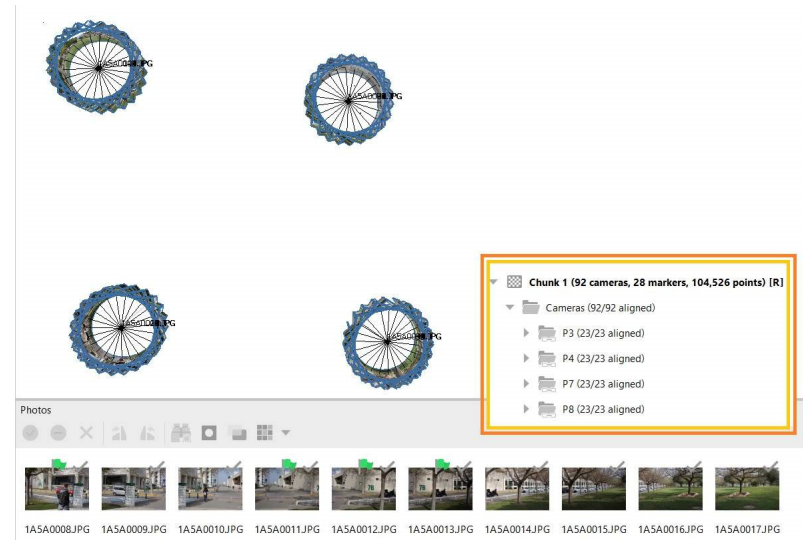

Figure 11: Orientation of four one strip panoramas made by Agisoft Metasfape software relative to each other from UPV campus.

\section{Results}

The results of making panoramic images using three different programs are reported next. Given that their results are comparable and the difference obtained can be considered significant. GigaPan Stitch software had a lot of parallax error in the images, which caused several breaks in the image, and this caused problems in the later stages of using panoramic images due to lack of proper quality. The lack of acceptable quality in the produced images can be seen in Figure 12. Unfortunately, in this software, it is not possible to check the geometric accuracy of the work numerically.

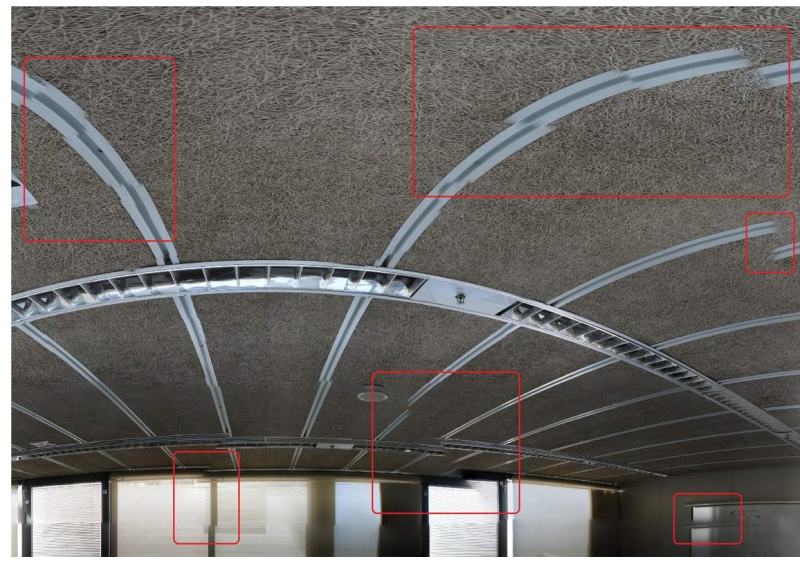

Figure 12: A cropped part of a spherical panoramic image made by GigaPan Stitch software and the images do not match correctly in the final output.

In the output obtained with PTGui software, the image quality was acceptable, but unfortunately, in some areas, minor fractures can be seen in the panoramic image. These fractures can be seen in Figure 13. These fractures are unpredictable or uncontrollable. Therefore, this fracture may occur in areas where we intend to examine or measure, and the work may be difficult. Of course, in the comparison study, the common points that this software has chosen are correct and acceptable in some cases.
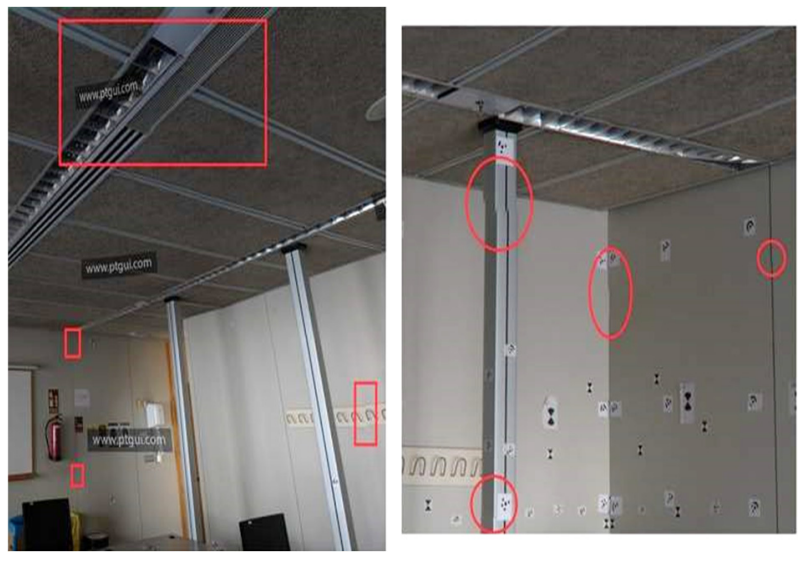

Figure 13: A cropped part of a spherical panoramic image made by PTGui software and the images do not match correctly in the final output.

Nevertheless, similar mismatches are not present in the Agisoft Metashape output. As it can be seen in Figure 14, both the quality and accuracy of the output panorama in Agisoft Metashape software can be considered good.

Then, considering the acceptable result obtained from the image quality of the spherical panorama, we decided to align the four spherical panoramas relative to each other. Due to the ability to automatically read coded targets by Agisoft Metashape software as well as automatic and manual matching, the next step is to reach the point cloud and the 3D model using these panoramic images. An 
example of low-density point cloud for one station inside the classroom is shown in Figure 15.

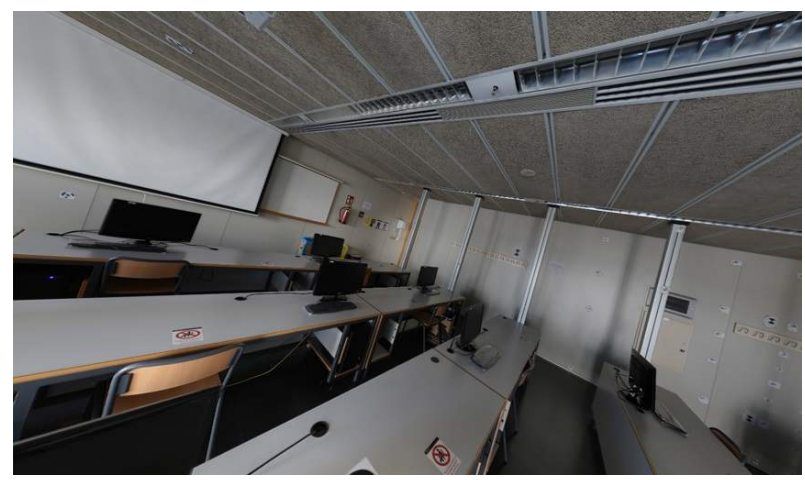

Figure 14: A cropped part of a spherical panoramic image made by Agisoft Metashape software.

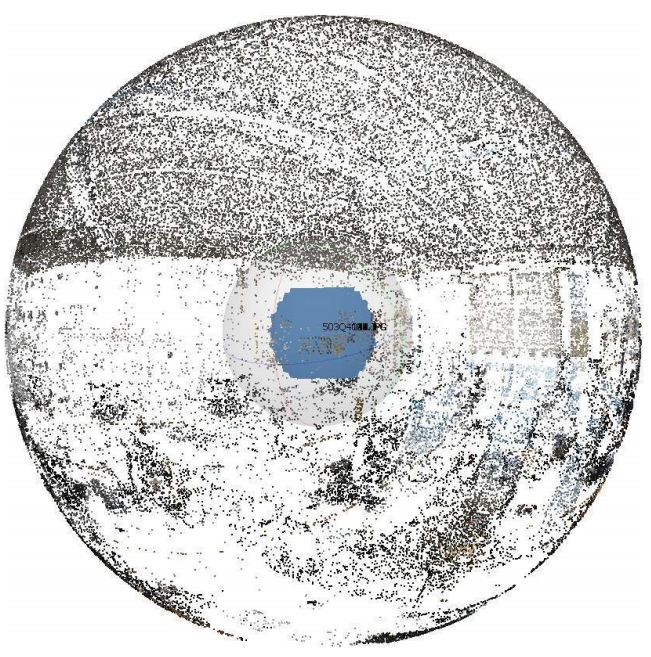

Figure 15: View of the formation of low-density points in the production of spherical panoramas after the alignment of images of a station.

The geometric accuracy achieved with the spherical panoramic images and information about the dense point cloud data is reflected in Tables 1, 2 and Figure 16.

Table 1: Data about the orientation of the four spherical panoramic images in the classroom.

\begin{tabular}{c|c} 
Data & Number \\
\hline Camera & 4 \\
Marker & 45 \\
Reference Points & 15 \\
Control Points & 14 \\
Check Points & 31 \\
Tie Points & 295 \\
Dense Points & 213.451
\end{tabular}

Table 2: Accuracy obtained in the orientation of the four spherical panoramic images in the classroom.

\begin{tabular}{c|c|c} 
Points & Error $(m)$ & Error (pix) \\
\hline Control Points & 0.026 & 11.64 \\
Check Points & 0.089 & 29.24
\end{tabular}

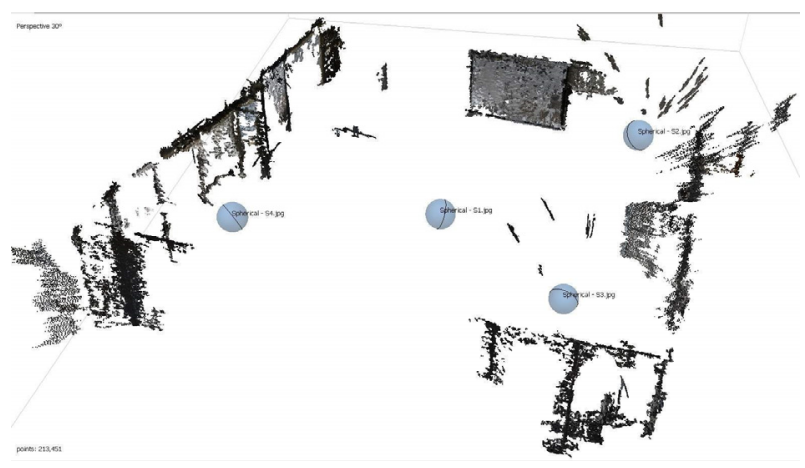

Figure 16: Dense point cloud produced after the orientation of the four spherical panoramas.

You can also see the geometric accuracy of the orientation of the panorama images in one horizontal strip and creating a dense cloud of points in Figure 17 and Tables 3 and 4.

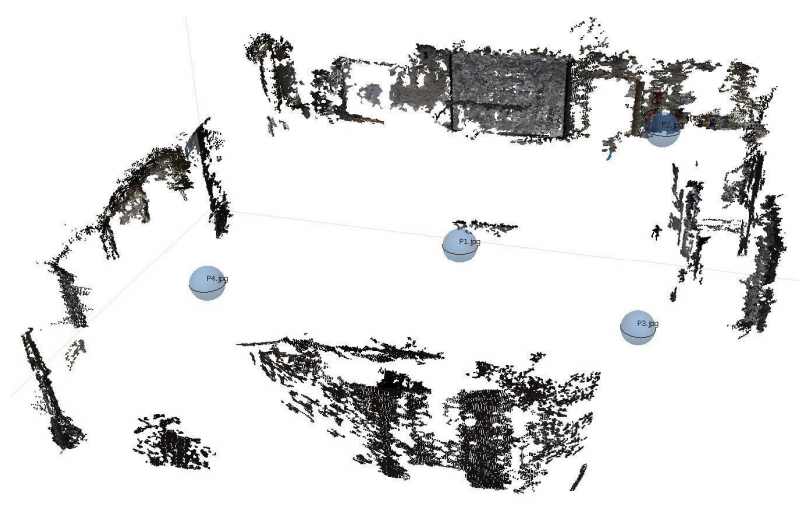

Figure 17: Dense point cloud generated by the orientation of the four panorama images in one horizontal strip.

Table 3: Data about the orientation of the four panoramic images in one horizontal strip in the classroom.

\begin{tabular}{c|c} 
Data & Number \\
\hline Camera & 4 \\
Marker & 9 \\
Reference Points & 6 \\
Control Points & 5 \\
Check Points & 4 \\
Tie Points & 443 \\
Dense Points & 129.707
\end{tabular}

Table 4: Accuracy obtained in the orientation of the four panoramic images in one horizontal strip in the classroom.

\begin{tabular}{c|c|c} 
Points & Error $(m)$ & Error (pix) \\
\hline Control Points & 0.009 & 2.72 \\
Check Points & 0.001 & 4.10
\end{tabular}

Considering the relatively long distance of the pillars from each other, the geometric accuracy obtained from the panorama images of the campus can be seen in Tables 5 and 6. 
Table 5: Data about the orientation of four panoramic images in one horizontal strip in the campus

\begin{tabular}{c|c} 
Data & Number \\
\hline Camera & 92 \\
Marker & 28 \\
Reference Points & 28 \\
Control Points & 7 \\
Check Points & 21 \\
Tie Points & 104526
\end{tabular}

Table 6: Template

\begin{tabular}{c|c|c} 
Points & Error $(m)$ & Error (pix) \\
\hline Control Points & 0.039 & 5.33 \\
Check Points & 0.067 & 0.86
\end{tabular}

\section{Discussion}

Various factors are involved in the geometric accuracy and quality of the images produced. There are some effective factors ranging from the conditions of the camera to the conditions of the environment. In panoramic photography, on the one hand, the selection of the appropriate camera and lens, and on the other hand, the selection of reliable software for stitching images are crucial in the accuracy and quality of the output images. As it is clear in the results, the accuracy of spherical panoramic images is very acceptable and if we do panoramic photography in one strip, its accuracy can be in the millimetre range. A key point is not to produce super and coherent point clouds when the object textures are not remarkable, which was the case of the indoor lab where the texture of walls, windows (glass), and the ceiling was rather simple and homogeneous. Thus, it turned out more effective to orient the images relative to each other and produce a $3 \mathrm{D}$ model than creating the $360^{\circ}$ panoramic image. Therefore, the framed images were eventually converted into spherical panoramas, then they were oriented relative to each other to yield the reported accuracy.

According to the results obtained from the software, it can be stated that Agisoft Metashape software can be considered a powerful and suitable software for producing panoramic images and model building. The main limitation seen in GigaPan Stitch is the impossibility of adding control points from a file or manually, as well as the possibility of manual matching. There also appeared problems working with PTGui software, such as the inability to check the geometric accuracy of the project. This software has higher facilities and accuracy than GigaPan Stitch software. The major items of the three softwares analysed are included in Table 7.
Table 7: Comparison of Agisoft Metashape, GigaPan Stitch and PTGui software.

\begin{tabular}{|c|c|c|c|}
\hline Setting & Agisoft & PYGui & GigaPan \\
\hline Import Formats & High & Low & Low \\
\hline Export Formats & High & Low & Low \\
\hline Export Raster Images & Yes & Yes & Yes \\
\hline $\begin{array}{l}\text { Export Technical Data } \\
(\text { camera, marker,...) }\end{array}$ & Yes & No & No \\
\hline Camera Calibration & Yes & No & Yes \\
\hline Exposure correction & Yes & No & Yes \\
\hline White balance correction & Yes & No & Yes \\
\hline Panorama leveling & Yes & No & Yes \\
\hline Lens distortion correcting & Yes & Yes & Yes \\
\hline $\begin{array}{l}\text { Partial or full (spherical) } \\
\text { panoramas or images from } \\
\text { panoramic cameras }\end{array}$ & Yes & Yes & Yes \\
\hline $\begin{array}{l}\text { Different focal lengths in a } \\
\text { single panorama }\end{array}$ & Yes & No & Yes \\
\hline $\begin{array}{l}\text { Different lens types in single } \\
\text { panorama }\end{array}$ & Yes & No & Yes \\
\hline Generate Report & Yes & No & No \\
\hline Accuracy and Errors Show & Yes & No & No \\
\hline Set Station & Yes & No & No \\
\hline Create 3D Model & Yes & No & No \\
\hline Workflow & Good & Poor & Normal \\
\hline User Friendly & Good & Poor & Poor \\
\hline Processing Speed/Time & Normal & Good & Poor \\
\hline
\end{tabular}

\section{Conclusions}

Taking into account that the aim of this research was the selection of reliable software for accurate and quality construction of spherical panoramic images and the subsequent use of these images for deformation monitoring, the correct evaluation of the tested software used is important for assessing different aspects such as image quality, workflow, processing speed, userfriendliness, or output of products/formats, all of them critical to the practical productivity of real projects. The results of the comparison show that Agisoft Metashape software meets the required geometric specifications with higher quality and has clear performance advantages compared to the other two tested programs. Also, considering the inappropriate texture of the environment inside the classroom, achieving $1 \mathrm{~mm}$ error using a singlestrip panorama and less than $7 \mathrm{~cm}$ can be considered acceptable for a spherical panorama. It is suggested to use this technique in future works, covering more targets in the upper and lower parts of the shooting area in order to achieve a better orientation with higher geometric accuracy.

\section{References}

BARBERO-GARCÍA, I., LERMA, J. L. and MORA-NAVARRO, G., 2020. Fully automatic smartphone-based photogrammetric 3D modelling of infant's heads for cranial deformation analysis. ISPRS Journal of Photogrammetry and Remote Sensing, 166, pp. 268-277. DOI: 10.1016/j.isprsjprs.2020.06.013 
CHUANG, T. Y. and PERNG, N. H., 2018. Rectified feature matching for spherical panoramic images. Photogrammetric Engineering and Remote Sensing, 84(1), pp. 25-32(8). DOI: 10.14358/PERS.84.1.25

DI Stefano, F., CABRElles, M., GARCíA-ASENJO, L., LERMA, J. L., MALINVERNI, E. S., BASELGA, S., GARRIGUES, P. and PIERDICCA, R., 2020. Evaluation of Long-Range Mobile Mapping System (MMS) and CloseRange Photogrammetry for Deformation Monitoring. A Case Study of Cortes de Pallás in Valencia (Spain). Applied Sciences, 10(19), 6831. DOI: 10.3390/app10196831

DUAN, Y., HAN, C., TAO, X., GENG, B., DU, Y., and LU, J., 2020. Panoramic Image Generation: From 2-D Sketch to Spherical Image. IEEE Journal of Selected Topics in Signal Processing, 14(1), pp. 194-208. DOI: 10.1109/jstsp.2020.2968772

FANGI, G., 2010. Multiscale multiresolution spherical photogrammetry with long focal lenses for architectural surveys. International Archives of Photogrammetry, Remote Sensing and Spatial Information Sciences, 38(Part 5), pp. 1-6.

FANGI, G., 2015. Documentation of some cultural heritage emergencies in Syria in August 2010 by spherical photrammetry. ISPRS Annals of the Photogrammetry, Remote Sensing and Spatial Information Sciences, 2(5), 401. DOI: 10.5194/isprsannals-II-5-W3-401-2015

FANGI, G., PIERDICCA, R., STURARI, M., and MALINVERNI, E. S., 2018. Improving spherical photogrammetry using $360^{\circ}$ omni-cameras: use cases and new applications. International Archives of the Photogrammetry, Remote Sensing \& Spatial Information Sciences, 42(2). DOI: 10.5194/isprs-archives-XLII-2-331-2018

FANGI, G. and NARDINOCCHI, C., 2013. Photogrammetric processing of spherical panoramas. Photogrammetric Record, 28(143), pp. 293-311. DOI: 10.1111/phor.12031

SZELISKI, R., 1996. Video mosaics for virtual environments. IEEE Computer Graphics and Applications, 16(2), pp. 2230. DOI: $10.1109 / 38.486677$

WANG, M., NIU, S. and YANG, X., 2017. A novel panoramic image stitching algorithm based on ORB. In Proceedings of the 2017 IEEE International Conference on Applied System Innovation: Applied System Innovation for Modern Technology, ICASI 2017, pp. 818-821. DOI: 10.1109/ICASI.2017.7988559

XIONG, Y. and TURKOWSKI, K., 1998. Registration, calibration and blending in creating high quality panoramas. In Proceedings - 4th IEEE Workshop on Applications of Computer Vision, WACV 1998, pp. 69-74. DOI: 10.1109/ACV.1998.732860 